\title{
Recto-Anal Biofeedback Treatment and Quality of Life in Children with Myelomeningocele
}

\author{
C. E. Zubiri'1, S. W. Miculan1, A. Zosi' ${ }^{1}$, G. I. Nanfito ${ }^{1 *}$, L. Guzman', P. Borobia', R. Bigliardi², \\ C. Arregui' ${ }^{1}$, V. Bernedo ${ }^{1}$, C. Otegui ${ }^{1}$, V. Valdiviezo' ${ }^{1}$, M. Allende ${ }^{1}$, M. A. Savia ${ }^{1}$, L. Menendez ${ }^{1}$, \\ A. Besga ${ }^{1}$, S. Morales ${ }^{1}$, R. Drut ${ }^{1}$, S. G. Tobia Gonzalez ${ }^{1}$, J. M. Dominguez ${ }^{1}$, A. G. Tortarolo¹, \\ H. A. Longuinho' ${ }^{1}$, Y. R. Gomez ${ }^{1}$, T. Gonzalez ${ }^{1}$
}

${ }^{1}$ Pediatric Hospital "Sor Maria Ludovica”, La Plata, Buenos Aires, Argentina

${ }^{2}$ Posadas Hospital, Buenos Aires, Argentina

Email: cecizubiri03@hotmail.com

How to cite this paper: Zubiri, C.E., Miculan, S.W., Zosi, A., Nanfito, G.I., Guzman, L., Borobia, P., Bigliardi, R., Arregui, C., Bernedo, V., Otegui, C., Valdiviezo, V., Allende, M., Savia, M.A., Menendez, L., Besga, A., Morales, S., Drut, R., Gonzalez, S.G.T., Dominguez, J.M., Tortarolo, A.G., Longuinho, H.A., Gomez, Y.R. and Gonzalez, T. (2019) Recto-Anal Biofeedback Treatment and Quality of Life in Children with Myelomeningocele. Open Journal of Epidemiology, 9, 202-212.

https://doi.org/10.4236/ojepi.2019.93017

Received: March 26, 2019

Accepted: August 4, 2019

Published: August 7, 2019

Copyright $\odot 2019$ by author(s) and Scientific Research Publishing Inc. This work is licensed under the Creative Commons Attribution International License (CC BY 4.0).

http://creativecommons.org/licenses/by/4.0/

\begin{abstract}
Introduction: Myelomeningocele is one of the most complex birth defects that cause physical disability, with consequent fecal incontinence and therefore difficulty in social integration of these patients. Objective: To improve the quality of life and manometric values after biofeedback therapy. Method: Longitudinal, prospective, analytical and experimental study. Patients with myelomeningocele and fecal incontinence who were between 5 to 15 years old and their parents were included in the study. Child and parent reports of PedsQMtm generic questionnaire were collected after obtaining informed consent and assent. Anorectal manometry and first biofeedback sessions were held with each child. Following treatment completion, the PedsQMtm was applied again. Results: 17 children and their parents were included in the study. All the patients presented fecal incontinence and an inability to voluntarily evacuate rectal contents. After biofeedback, the totality of patients improved their fecal incontinence. Nine of them stop using diaper. All reported successful use of the toilet. Statistically significant differences were observed when comparing the quality of life of children and parents at the beginning and at the end of treatment. There was an improvement in quality of life after the treatment with biofeedback for both children and parents, which was more perceived by these. Conclusions: It is highly significant for the improvement both in clinic and manometric values. The improvement in quality of life is more evident in the parents.
\end{abstract}

\section{Keywords}

Biofeedback, Fecal Incontinence, Manometry, Myelomeningocele, Quality of Life

${ }^{*}$ The author is dead. 


\section{Introduction}

Myelomeningocele is the most common congenital defect causing physical disability in human beings, representing the most severe expression of bifid spine. Medial world incidence is $1 / 2000$ births, but with important geographic variations [1] [2] [3] [4].

This condition implies the absence of nerves which normally inervate the structures destinated to determine vesico-urethral and ano-rectal continence [5] [6].

The resulting fecal incontinence is a barrier for the social integration of these children and adolescents. At the same time, there is a psychologic damage resulting in loss of self esteem and derangement of quality of life [7] [8].

There are a great number of different therapeutic treatments for fecal incontinence [9]-[18].

In this paper, we propose the re-education of the anal sphincter through bio-feedback as the treatment of fecal incontinence. This allows the patient to understand the physiology of defecation and to correct its sensitive and motor alterations. Studies report good results up to $50 \%-85 \%$ in the bowel continence; $25 \%$ of them improving fecal and urinary continence [14] [19] [20] [21] [22] [23].

The treatment depends in great part on the doctor-patient relationship; that explains the variations in the percentage of success. The prevalence of fecal incontinence in patients with myelomeningocele ranges between $70 \%$ and $89 \%$, numbers which underline the importance of searching a solution for them [5]-[24].

In these patients with chronic diseases is not only important the evidence of clinical improvement but also the Quality of Life, not only for children themselves but also for their parents. The quality of life is a unique and personal subject. It is the subjective perception of how a person feels as to his/her health state and the non-medical aspects of his/her life [25]-[32].

In order to evaluate Quality of Life we used the PedsQL, an instrument developed in United States by James Varni in the 90's.

There are several papers about fecal incontinence of these children and its psycho-social effects, but the quality of life of these patients has been rarely analyzed [5] [33].

The objective of this work is to improve the quality of life of children with myelomeningocele with an age between 5 and 15 years, with fecal incontinence, assisted in our hospital by performing recto-anal manometry followed by session of biofeedback.

Another objective is to evaluate if with such treatment, fecal continence or an evident improvement of the clinical condition is obtained, as well as modifications in the sensitivity and voluntary contraction.

The recto-anal biofeedback is a simple method which allows to detect the cause of the incontinence in each patient and to obtain, in some patients, the possibility of partial or total improvement of it along the several sessions [5] [21]. 


\section{Material and Methods}

This has been a longitudinal, prospective, analytic and experimental study. In it were included 24 children ( 5 to 15 years of age) with myelomeningocele and fecal incontinence, and their parents, assisted between March 2014 and March 2015. Of these 17 completed the studies and the treatment.

Besides the whole context already referred to it was necessary that the patients had the mental capacity to collaborate. So, those without the latter condition remained excluded.

In order to participate, a document signed by the parents or the taking-care person was required, as well as the consent of the child older than 8 years. The sample was selected by convenience and not aleatory. Each patient was included the same day in which the questionary was filled (see from in Anexus 1). This form contains personal data, clinical history, and the variables resulting from the initial manometry and the last biofeedback treatment session (Anexus 1: Protocol for patients with myelomeningocele and fecal incontinence).

The following were the variables which were measured:

1) Basal pressure of the anal canal (BPAC): it allows to maintain continence. Approximately $55 \%-80 \%$ of this pressure results from the internal anal sphincter (IAS) activity. Its fibers mainly concentrate at $1-2 \mathrm{~cm}$ of the internal anal margin. Its activity is mainly neurologic and to a lesser degree also myogenous.

The BPAC can be measured in 2 ways: 1) Mean of 4 measures at different sites of the higher pressure of the anal canal at rest, or 2) Mean pressure at each site. Normal value: 40 - $75 \mathrm{mmHg}$.

2) Higher pressure of the anal canal: when the patient contracts to avoid passing fecal material. Normal value: more than $100 \mathrm{mmHg}$.

3) Rectal sensitive level: minimal volume of rectal distention that the patient is able to discriminate. It is defined as the first sensation registered to the smaller quantity of air volume insufflated in the rectum through a balloon. Normal value: 10 - $40 \mathrm{cc}$.

4) Voiding sensation: the minimal volume awakening the voiding wish. Normal value 40 - $60 \mathrm{cc}$.

5) Maximal tolerance volume: the intrarectal volume insufflated resulting in pain or persistent discomfort. The maximal volume of air to be insufflated searching for it is $300 \mathrm{cc}$. Normal value: $100-300 \mathrm{cc}$.

These were the normal values which were taken into consideration but due to the great variations of data of the several published reports we stressed on the initial value obtained in each patient and its comparison with the number obtained at the end of the treatment [5] [22] [34].

As to the PedsQL ${ }^{\mathrm{tm}}$ it is a generic module designed to measure quality of life as related to the health of healthy children and adolescents and those with acute or chronic diseases. The author gave us license to use this module with scientific aims. There is a Spanish version of this document [35] [36] [37]. It contains 23 
items, with an age range from 2 to 18 years, a form for self-report and one for the parents. It includes the physical, emotional, social and school behavior. Due to it psychometric properties it is recommended for clinical use and for comparisons between groups. This form cannot be published but the results can [26] [27] [37]. The questionnaire will be referred to following the Guide for Administration of PedsQL ${ }^{\mathrm{tm}}$ [5] [33].

After obtaining the answers to the questionnaire the first step was to perform the initial manometry, a perfusion conventional manometry.

The procedure consisted in introducing through the anus, a recto-anal manometry probe through water perfusion with a balloon, (previously covered with a preservative without latex), up to $10 \mathrm{~cm}$ within the rectum. The probe was slowly removed in order to identify the anal canal, measuring the pressure at rest, its length and the distance of the anal margin. In order to evaluate the recto-anal motility the patient was asked to cough, to measure the response to cough, to contract and close the anus (measuring the pressures) and after at least 20 seconds it was asked to push. At this moment the patient was taught which were the exercises that he/she should do at home, reproducing what was previously done. After this stage we continued with the sensitivity tests with increasing pressures of the balloon, evaluating the rectal sensitivity level, defecate sensivity and largest tolerance volume.

Afterwords it was proceeded to measure the recto-anal inhibitory reflex with progressive and repeated inflations.

After ending this initial manometry the patients were cited for beginning the bio-feedback session. The patient received oral and written data about the contraction and relaxation exercises that they should do at home 3 times a day, all days, until de next meeting.

In the first bio-feedback session a rectal probe was introduced with the patient looping at the computer screen, in order that he/she could see how the pressure curves changed while the contraction and pushing exercises were done.

Each activity consisted in a contraction followed by a push, first with an empty balloon and then inflating it untill obtaining the defecate sensation; at this moment the exercises of contraction and push were done again. Depending on the patient predisposition each session included 4 to 6 exercises.

In each session the rectal sensitivity, the muscle strength and the pushing were measured in order to get data about the achieved changes.

Once the treatment was finished a new version of the questionnaire PedsQM ${ }^{\mathrm{tm}}$. was obtained.

The descriptive analysis of the information was done with the Epi Info 2006 program [38]. For the data analysis the following statistical programs were also used: the Student test, Chi square and Fisher program.

According to the instructions of PedsQL ${ }^{\mathrm{tm}}$ it was considered as valid the form which presented complete and valid $50 \%$ or more of the questions of each section, in order to get the total add. The results were informed as total value and at the same time, the emotional, social, scholar and physical sections separately. 
All the results were informed as mean and standard deviation or as median and intervals, according to the distribution of the variables.

This research protocol was evaluated and approved by the Ethics Committee of the Instituto de Desarrollo e Investigaciones Pediátricas (IDIP) of the Hospital which, at the same time, is authorized by the Central Ethics Committee of the Ministry of Health of Buenos Aires Province.

\section{Results}

Initially, 24 patients were included in the study from which 17 completed the study ( 8 women and 9 men), with a median of 8.8 years at the beginning.

Patients were divided in three groups according to age with similar capacity of interpretation; group 1: (9 patients) $5-7$ years; group 2: (3 patients) 8 - 12 years and group 3: (5 patients) $13-15$ years.

All completed adequately the questionnaire at the beginning and the end of the biofeedback sessions. The total number of sessions were 81 (mean 4765/patient) (median: 5; mode: 6; standard deviation: 1.52); minimal number of sessions: 2; maximum number of sessions: 6 .

All 17 patients we able to complete the biofeedback sessions and the forms of Quality of life at the beginning and at the end of the treatment, without any problems. The form was easy to fill in and, in most cases, either the patients or their parents did not need help. Only in the case of a deaf-mute child it was necessary to help him complete the form.

The average of sessions done to patients was 4.7 sessions (range 2 - 6).

Basal characteristics of patients are described in Table 1.

Results obtained in initial manometry and comparition with recto-anal manometry done at the end of treatment is displayed in Table 2.

By the end of treatment, the average of voluntary contraction was $65 \mathrm{mmHg}$ (range 15 - 150).

It was highly significant the improvement of voluntary contraction after treatment $(\mathrm{p}<0.00002)$.

Sensitivity (defecatory sensation) after treatment reach a median of $65 \mathrm{cc}$, showing a highly significant difference, in contrast to the numbers at the beginning of treatment $(\mathrm{p}=0.004)$.

Although 7 patients presented fecal incontination by the end of treatment, frequency decreased from the one at the beginning (one or twice per week) ( $\mathrm{p}=$ 0.0002088).

Nine patients stop using diapers. The rest of patients, $6(35.3 \%)$ used it occasionally and $2(11.8 \%)$ permanently $(\mathrm{p}=0.0005674)($ Chi cuadrado $=11.88)$, being the difference highly significant.

It is worth mentioning that 3 patients that were wheel chair dependent, achieve complete fecal continence and stop using diapers.

Initially, none of the group of study used the toilet; by the end of treatment $16(94.1 \%)$ patients had learned how to use it (Chi cuadrado $=29.33)(\mathrm{p}=$ $0.0000001)$. 
The analysis of the answers of the Quality of life test, both for parents and patients at the beginning and end of treatment, are displayed in Table 3 and Table 4.

By using Student Test and P-value, it was compared the different age ranges, and quality of life test results, done at the beginning and end of treatment. The analysis is displayed in Table 5 and Table 6.

Table 1. Basal Characteristics of patients.

\begin{tabular}{cc}
\hline Basal Characteristics & Percentage of children \\
\hline Proper growth & $100 \%$ \\
Defecatory Sensation & $35 \%$ \\
Use of enema or laxatives & $30 \%$ \\
Diminished sphincter tone & $70 \%$ \\
Use of dippers due to soiling & $100 \%$ \\
Presence of anal skin reflex & $17,6 \%$ \\
Urinary Incontinence & $100 \%$ \\
School attendance & $100 \%$ \\
Ventriculoperitoneal valve & $59 \%$ \\
Wheelchair need & $18 \%$ \\
Mobility with orthopedic equipment & $12 \%$ \\
\hline Walks with difficulty, without orthopedic equipment & $70 \%$ \\
\hline
\end{tabular}

Table 2. Manometric data at the beginning and end of treatment.

\begin{tabular}{ccccc}
\hline Manometric Data & \multicolumn{2}{c}{ Initial Manometry } & \multicolumn{2}{c}{ Final Manometry } \\
\hline & Number of cases Percentage & Number of cases Percentage \\
\hline Anal contraction movement & 14 & $82 \%$ & 17 & $100 \%$ \\
Normal voluntary contraction & 1 & $5.8 \%$ & 3 & $17.6 \%$ \\
Presence of push movement & 17 & $100 \%$ & 17 & $100 \%$ \\
Presence of sensitivity & 11 & $64.7 \%$ & 17 & $100 \%$ \\
Normal Sensitivity & 6 & $35.2 \%$ & 12 & $70.5 \%$ \\
Rectoanal inhibitory reflex & 17 & $100 \%$ & 17 & $100 \%$ \\
\hline
\end{tabular}

Table 3. Quality of life test in parents at the beginning and end of treatment.

\begin{tabular}{ccccccc}
\hline Aspect & \multicolumn{7}{c}{$\mathrm{N}=17$} \\
\hline & Beginning of treatment & \multicolumn{2}{c}{ End of treatment } & Student test (t) & Value of P \\
\hline & Mean & Range & Mean & Range & & 0.04 \\
Physical & 50 & $6-94$ & 67 & $19-100$ & -2.11 & -0.52 \\
Emotional & 62 & $25-100$ & 71 & $20-100$ & -1.27 & 0.20 \\
Social & 62 & $20-100$ & 72 & $25-100$ & -0.29 & 0.77 \\
School & 64 & $10-100$ & 67 & $15-100$ & -1.42 & 0.16 \\
Total & 59 & $24-97$ & 68 & $22-100$ & & \\
\hline
\end{tabular}


Table 4. Quality of life test in children at the beginning and end of treatment.

\begin{tabular}{ccccccc}
\hline Aspect & \multicolumn{7}{c}{$\mathbf{N = 8}$} \\
\hline & \multicolumn{7}{c}{ Beginning of treatment } & \multicolumn{2}{c}{ Endo f treatment } & Student $(\mathrm{t})$ Test & Value of $\mathbf{P}$ \\
\hline & Mean & Range & Mean & Range & & \\
\hline Physical & 61 & $41-79$ & 59 & $28-97$ & -0.39 & 0.70 \\
Emotional & 66 & $20-100$ & 71 & $15-100$ & -0.37 & 0.71 \\
Social & 78 & $20-100$ & 79 & $30-100$ & -0.04 & 0.96 \\
School & 42 & $15-80$ & 54 & $20-85$ & -1.11 & 0.28 \\
Total & 62 & $25-75$ & 66 & $25-93$ & -0.38 & 0.70 \\
\hline
\end{tabular}

Table 5. Quality of life in parents whose children abandoned the use of diaper.

\begin{tabular}{ccccccc}
\hline Aspect & \multicolumn{7}{c}{$\mathbf{N = 9}$} \\
\hline & Beginning of treatment & \multicolumn{2}{c}{ End of treatment } & Student ( $\mathrm{t}$ ) Test & Value of $\mathbf{P}$ \\
\hline & Mean & Range & Mean & Range & & \\
\hline Physical & 44 & $6-69$ & 76 & $47-100$ & -2.11 & 0.04 \\
Emotional & 62 & $30-100$ & 79 & $35-100$ & -0.52 & 0.60 \\
Social & 65.5 & $40-100$ & 80.5 & $60-100$ & -1.27 & 0.20 \\
School & 62 & $25-90$ & 80 & $55-90$ & -0.29 & 0.77
\end{tabular}

Table 6. Quality of life test in children who abandoned the use of diaper.

\begin{tabular}{ccccccc}
\hline Aspect & \multicolumn{7}{c}{$\mathbf{N = 6}$} \\
\hline & Beginning of treatment & \multicolumn{2}{c}{ Endo f treatment } & Student $(\mathrm{t})$ Test & Value of P \\
\hline & Mean & Range & Mean & Range & & \\
\hline Physical & 60 & $40-79$ & 65.5 & $28-97$ & -0.39 & 0.70 \\
Emotional & 72 & $50-100$ & 78 & $55-100$ & -0.66 & 0.52 \\
Social & 86 & $70-100$ & 91 & $65-100$ & -0.65 & 0.52 \\
School & 43 & $20-80$ & 56 & $30-85$ & -1.73 & 0.18 \\
\hline
\end{tabular}

By the end of the study, the emotional aspect reached similar values both in children and adults. At the beginning, adults' values were lower than children, without statistical significance.

When comparing social aspect, statistical significance $(\mathrm{p}=0.046)$ was found between parents (64 points) and their sons (78 points).

In school aspect, parents referred remarkable improvement in this field, not being considered so in children. The difference between groups was statistically significant $(\mathrm{p}=0.033)$.

The statistical analysis of the Quality of life tests performed at the beginning and at the end of the treatment performed to the patients who were able to stop using diapers and their parents are presented in Table 3.

\section{Discussion}

The overall aim of this project was to improve que quality of life of children with 
myelomeningocele within an age of 5 to 15 years, with fecal incontinence, performing recto-anal manometry followed by session of biofeedback.

While evaluating the results of the test performed before the treatment to the parents as well as that to the children, we found that the later showed better results than those of the parents and a more positive view in all the features (social, emotional, school and physical). It is possible that these children had developed stronger strategies and psychosocial habilities than those of their parents since they were born with the condition and assume it daily as such.

When comparing the data obtained in the enquire done to the children and their parents the differences resulted statistically significative, mainly in its social and emotional features.

At the end of the treatment all the patients showed better results in the test but these were not statistically significative since the numbers of the first were high. This was not so in the parents in whom the test results the differences between the first and the end test were higher and statistically significative as to the physical features and a tendency to be so in the emotional features.

As limiting data it could be mentioned that the generic Quality of life for pediatric patients used in this research did not accurately reflex the important changes and improvements which were clinically recognized in these children. The ideal would be to use a specific Test for this pathology. This was not so because there is none accurately validated at this time for the pediatric age.

As to the specific objectives implying clinical and manometric evident changes at the end of the treatment, these showed important modifications and all of them being statistically highly significative when comparing the beginning and end.

The sensitivity was achieved in $100 \%$ of the patients and those who had it obtained an improvement, many of them resulting in normal values.

As to the voluntary contraction which is more difficult to obtain in these children, it was achieved by $100 \%$ of the patients, of whom 3 reached normal values.

All these achievements led to the fact that more than $50 \%$ of the children obtained fecal continence and, by so doing, stopped using diapers.

All the patients began using the toilet. This is not just a simple data since it implies the beginning of the independence for these children.

\section{Conclusion}

According to the results obtained in this project, it is concluded that it is essential for all patients with myelomeningocele and fecal incontinence to be evaluated by a multidisciplinary team in which a pediatric gastroenterologist should be included. By doing it so, each patient will receive treatment opportunities according to what best fits to his/her needs obtaining an improvement not only of the fecal incontinence, but also of the quality of life of the patient and his/her family. 


\section{Conflicts of Interest}

The authors declare no conflicts of interest regarding the publication of this paper.

\section{References}

[1] Eric, G.R., Detrait, A., Timothy, M., et al. (2005) Human Neural Tube Defects: Developmental Biology, Epidemiology and Genetics. Neurotoxicology and Teratology, 27, 515-524. https://doi.org/10.1016/j.ntt.2004.12.007

[2] Johnston, M.V. and Kinsman, S. (2005) Anomalías Congénitas del Sistema Nervioso Central. In: Kliegman, R.M., Behrman, R.E. and Jenson, H.B., Eds., Nelson Tratado de Pediatría, 17th Edición, Elsevier, Madrid, 1983-1993.

[3] Zucccaro, G. (2005) Tratamiento Prenatal del Mielomeningocele. In: Boletín del Departamento de Docencia e Investigación del Instituto de Rehabilitación psicofísica, Instituto de Rehabilitación Psicofísica, Vol. 9, 24-27.

[4] Vallejos Mearra, N., Rossitto, V., Lagarreta, C., et al. (2005) Tratamiento de las Deformidades Espinales por Mielomeningocele. In: Boletín del Departamento de Docencia e Investigación del Instituto de Rehabilitación psicofísica, Instituto de Rehabilitación Psicofísica, Vol. 9, 44-48.

[5] Blanco Fernández, G., Blesa Sierra, I., Núñez Núñez, R., et al. (2002) Reeducación del esfínter anal en el mielomeningocele. Anales Españoles de Pediatría, 56, 111-115. https://doi.org/10.1016/S1695-4033(02)78940-6

[6] Sánchez Martín, R., Barrientos Fernández, G., Arrojo Vila, F., et al. (1999) El obturador anal en el tratamiento de la incontinencia fecal en el mielomeningocele: Resultados del primer ensayo clínico. Anales Españoles de Pediatría, 51, 489-492.

[7] Vu Minh Arnell, M., Seljee Svedberg, K., Lindehall, B., et al. (2013) Health-Related Quality of Life Compared to Life Situation and Incontinence in Adults with Myelomeningocele: Is SF-36 a Reliable Tool? Journal of Pediatric Urology, 12, 1477. https://doi.org/10.1016/j.jpurol.2013.05.005

[8] Mínguez Pérez, M. and Benages Martínez, A. (2004) Calidad de vida en los pacientes con incontinencia anal. Gastroenterology \& Hepatology, 27, 39-48. https://doi.org/10.1157/13058929

[9] Schmidt, R.A., Kogan, B.A. and Tanagho, E.A. (1990) Neuroprostheses in the Management of Incontinence. Journal of Urology, 143, 779-782. https://doi.org/10.1016/S0022-5347(17)40092-9

[10] Corbett, P., Denny, A., Dick, K.M., et al. (2014) Peristeen Integrated Transanal Irrigation System Successfully Treats Faecal Incontinence in Children. Journal of Pediatric Urology, 10, 219-222. https://doi.org/10.1016/S0022-5347(17)40092-9

[11] Malone, P.S., Rasley, P.G. and Kiely, E.M. (1990) Preliminary Report: The Anterograde Continence Enema. The Lancet, 336, 1217-1220. https://doi.org/10.1016/0140-6736(90)92834-5

[12] Masadeh, M.M., Krein, M., Petersin, J., et al. (2013) Outcome of Antegrade Continent Enema (ACE) Procedures in Children and Young Adults. Journal of Pediatric Surgery, 48, 2128-2133. https://doi.org/10.1016/j.jpedsurg.2013.04.009

[13] Shandling, B. and Gilmour, R.F. (1987) The Enema Continence Catheter in Spina Bifida: Sucessful Bowel Management. Journal of Pediatric Surgery, 22, 271-273. https://doi.org/10.1016/S0022-3468(87)80345-7

[14] Fernández Eire, P., Varela Cives, R. and Castro Gago, M. (1998) Tratamiento 
conservador de la incontinencia fecal neurógena. Nuestra experiencia en la edad pediátrica. Anales Españoles de Pediatría, 48, 256-260.

[15] Carter, D. (2014) Conservative Treatment for Anal Incontinence. Gastroenterology Report, 2, 85-91. https://doi.org/10.1093/gastro/gou013

[16] Shandling, B.B., Chait, P.G. and Richards, H.F. (1996) Percutaneous Cecostomy: A New Technique in the Management of Fecal Incontinence. Journal of Pediatric Surgery, 31, 534-537. https://doi.org/10.1016/S0022-3468(96)90490-X

[17] Heidemarie Hinninghofen, P. and Enck, P. (2003) Fecal Incontinence: Evaluation and Treatment. Gastroenterology Clinics of North America, 32, 685-706. https://doi.org/10.1016/S0889-8553(03)00021-9

[18] Del Río, C., Biondo, S. and Martí Ragué, J. (2005) Incontinencia Fecal. Valoración del Paciente. Tratamientos Clásicos. Cirugía Española, 78, 34-40. https://doi.org/10.1016/S0009-739X(05)74642-X

[19] Rao, S.S.C., Benninga, M.A., Bharucha, A.E., et al. (2015) ANMS-ESNM Position Paper and Consensus Guidelines on Biofeedback Therapy for Anorectal Disorders. Neurogastroenterology \& Motility, 27, 594-609. https://doi.org/10.1111/nmo.12520

[20] Azpiroz, F., Aparici, A., et al. (2003) Predictors of Response to Biofeedback Treatment in anal Incontinence. Diseases of the Colon \& Rectum, 46, 1218-1225. https://doi.org/10.1007/s10350-004-6718-7

[21] Rao, S.S., Seaton, K., Miller, M., et al. (2007) Randomized Controlled Trial of Biofeedback, Sham Feedback, and Standard Therapy for Dyssynergic Defecation. Clinical Gastroenterology and Hepatology, 5, 331-338. https://doi.org/10.1016/j.cgh.2006.12.023

[22] de los Ríos, C.C., et al. (2010) Diferencias en las presiones del canal anal y la sensibilidad rectal en pacientes con incontinencia anal, estreñimiento crónico y sujetos sanos. Revista Espanola De Enfermedades Digestivas, 102, 683-690. https://doi.org/10.4321/S1130-01082010001200002

[23] Wong, U.R. (2006) Manometría Ano-rectal, Perspectivas Actuales. Revista del Hospital Juárez de México, 73, 28-32.

[24] Vande Valde, S., Van Biervliet, S., Van reterghem, K., et al. (2007) Achieving Fecal Continence in Patients with Spina Bífida: A Descriptive Cohort Study. Journal of Urology, 178, 2640-2644. https://doi.org/10.1016/j.juro.2007.07.060

[25] Poley, M. (2007) Explaining Change in Quality of Life of Children and Adolescents with Anorectal Malformations or Hirschprung Disease. Pediatrie, 119, 374-383. https://doi.org/10.1542/peds.2006-0212

[26] Roizen, M., Figueroa, C. and Salvia, L. (2007) Miembros del Comité de Calidad de Vida y Salud. Calidad de vida relacionada con la salud en niños con enfermedades crónicas: Comparación de la visión de los niños, sus padres y sus médicos. Archivos Argentinos de Pediatria, 105, 305-313.

[27] Garrahan, J.P. (2004) Comité de Calidad de Vida Relacionada a la Salud. Hospital de Pediatría. Calidad de vida relacionada a la salud. Medicina Infantil del Hospital de Pediatría, 11, 301-305.

[28] Bazo, M. and Bailez, M. (2013) Calidad de vida relacionada con la salud en niños y adolescentes con cirugía de enfermedad de Hirschsprung y malformaciones anorrectales. Archivos Argentinos de Pediatria, 111, 37-44.

https://doi.org/10.5546/aap.2013.37

[29] Rocque, B.G., Bishop, E.R., Scogin, M.A., et al. (2015) Assessing Health-Related Quality of Life in Children with Spina Bifida. Journal of Neurosurgery-Pediatrics, 
15, 144-149. https://doi.org/10.3171/2014.10.PEDS1441

[30] Wang, J.C., Lai, C.J. and Wong, T.T. (2013) Health-Related Quality of Life in Children and Adolescents with Spinal Dysraphism: Results from a Taiwanese Sample. Child's Nervous System, 29, 1671-1679. https://doi.org/10.1007/s00381-013-2117-5

[31] Bartonek, A., Saraste, H. and Danielsson, A. (2012) Health-Related Quality of Life and Ambulation in Children with Myelomeningocele in a Swedish Population. Acta Paediatrica, 101, 953-956. https://doi.org/10.1111/j.1651-2227.2012.02742.x

[32] Buffart, L.M., van den Berg-Emons, R.J., van Meeteren, J., et al. (2009) Lifestyle, Participation, and Health-Related Quality of Life in Adolescents and Young Adults with Myelomeningocele. Developmental Medicine \& Child Neurology, 51, 886-894. https://doi.org/10.1111/j.1469-8749.2009.03293.x

[33] Di Lorenzo, C., Hillemeier, C., Hyman, P., et al. (2002) Manometry Studies in Children: Minimum Standards for Procedures. Neurogastroenterology \& Motility, 14, 411-420. https://doi.org/10.1046/j.1365-2982.2002.00347.x

[34] Wald, A. (1981) Biofeedback Therapy for Fecal Incontinence. Annals of Internal Medicine, 95, 146-149. https://doi.org/10.7326/0003-4819-95-2-146

[35] PedsQl ${ }^{\mathrm{TM}}$ Website. http://www.pedsql.org/about pedsql.html

[36] Varni, W. (2008) PedsQ1 ${ }^{\mathrm{TM}}$ Administration Guidelines. http://www.pedsql.org/pedsqladmin.html

[37] Varni, W. (2008) PedsQ1 ${ }^{\mathrm{TM}}$ Scoring Algorithm. http://www.pedsql.org/score.html

[38] Centers for Disease Control and Prevention (1994) Epi Info [Computer Program]. Version 6. Atlanta. 